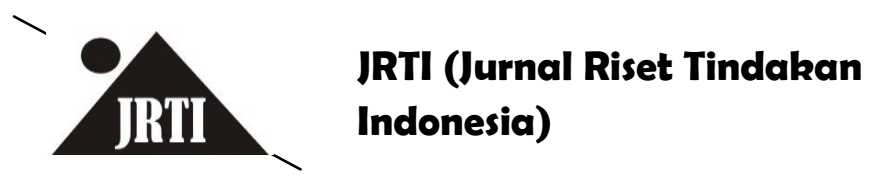

Volume 4 Nomor 2, Desember 2019, hlm 53-58

ISSN: 2502-079X (Print)

ISSN: 2503-1619 (Electronic)

Info Artikel:

Diterima: 30/12/2020

Direvisi: 26/01/2020

Dipublikasikan: 26/02/2020

Dipublikasikan oleh:

Indonesian Institute for Counseling, Education and Therapy (IICET)

Akses Online :

http://jurnal.iicet.org/index.php/irti

\title{
Perkembangan Kabupaten Solok setelah otonomi daerah tahun 1998-2019
}

\author{
Sawatul Zamra ${ }^{1}$, Ernawati ${ }^{2}$ \\ ${ }^{1}$ Pasca Sarjana Universitas Negeri Padang \\ ${ }^{2}$ Universitas Negeri Padang
}

\begin{abstract}
:
This study aims to describe the economic changes and social and cultural development in Solok Regency after regional autonomy. The approach used in this study is a qualitative approach. Data collection is done by interview, observation, and documentation. Data analysis techniques used in this study are as proposed by Milles and A. Huberman which consists of several stages, namely data reduction, data presentation, and drawing conclusions. There are economic changes and development in Solok Regency from the aspects of agriculture, housing and electricity. While changes that occur in social and cultural aspects are seen from the activities of handling people with social welfare problems and activities that support cultural preservation such as arts and cultural festivals.
\end{abstract}

Keyword: Change, solok regency, regional autonomy

This is an open access article distributed under the Creative Commons Attribution License, which permits unrestricted use, distribution, and reproduction in any medium, provided the original work is properly cited. (C2019 by author

\section{PENDAHULUAN}

Implementasi dari pelaksanaan reformasi dewasa ini telah melahirkan suatu konsep penyelenggaraan pemerintah, yakni pelimpahan kekuasaan pada setiap kabupaten dan kota untuk mengatur dan mengurus rumah tangganya sendiri. Secara formal, berdasarkan Undang-Undang Nomor 32 Tahun 2004 tentang Pemerintahan Daerah, desentralisasi diartikan sebagai penyerahan kewenangan pemerintah oleh Pemerintah kepada Daerah Otonom dalam kerangka Negara Kesatuan Republik Indonesia. Tujuan pemberian otonomi daerah yaitu untuk memungkinkan daerah yang bersangkutan mengatur dan mengurus rumah tangganya sendiri untuk meningkatkan daya guna dan hasil guna penyelenggaraan pemerintahan (Kuncoro, 2004).

Dengan merujuk kepada Undang-undang nomor 22 tahun 1999 tentang Pemerintahan Daerah, pemerintah kabupaten/kota diberikan kewenangan yang nyata dan luas serta tanggung jawab penuh untuk mengatur daerahnya masing-masing. Kabupaten Solok yang saat itu memiliki luas 7.084,2 $\mathrm{Km}^{2}$ dan memiliki kesempatan untuk melakukan penataan terhadap wilayah administrasi pemerintahannya. Penataan pertama dilakukan pada tahun 1999 dengan menjadikan wilayah kecamatan yang pada tahun 1980 ditetapkan sebanyak 13 kecamatan induk ditingkatkan menjadi 14 sementara jumlah desa dan kelurahan masih tetap sama. 
Pelaksanaan otonomi daerah selain berlandaskan pada acuan hukum, juga sebagai implementasi tuntutan globalisasi yang harus diberdayakan dengan cara memberikan daerah kewenangan yang luas, lebih nyata dan bertanggung jawab, terutama dalam mengatur memanfaatkan dan menggali sumber-sumber potensi yang ada di daerah masing-masing (Ristanti \& Handoyo, 2017). Melalui kebijakan desentralisasi dan otonomi daerah maka pengambilan keputusan dalam penyelenggaraan pemerintahan dan penyediaan pelayanan publik diharapkan akan menjadi lebih sederhana dan cepat karena dapat dilakukan oleh pemerintah daerah terdekat sesuai kewenangan yang ada. Hal ini berdasarkan asumsi bahwa pemerintah kabupaten dan kota memiliki pemahaman yang lebih baik mengenai kebutuhan dan aspirasi masyarakat mereka dari pada pemerintah pusat (Triani, 2015).

Akan tetapi, pembangunan daerah tidak selau berdampak positif. Idenfikasi pengaruh pelaksanaan otonomi daerah juga berpengaruh signifikan terhadap ketimpangan dan perkembangan yang terjadi di masyarakat (Anggun Ciptasari Nurana; Lutfi Muta'ali, 2009). Perkembangan dan perubahan drastis dengan kewenangan yang diberikan, tidak diimbangi dengan kerangka hukum yang stabil juga mengakibatkan ekspresi cultural shock sehingga kasus deviasi kewenangan bermunculan di daerah (Ristanti \& Handoyo, 2017).

Permasalahan lain yang dihadapi oleh otonomi daerah yaitu Pemerintah kota dan kabupaten yang merasa pesisimis dengan dengan kemampuan pendapatan asli daerah PAD yang diharapkan untuk membiayai pembangunan. Kegamangan juga ikut mendorong terbunuhnya ide-ide dan kreativits pejabat daerah dalam merencanakan program pembangunan. Padahal jika hanya mengandalkan perintah dari pusat, maka dengan sendirinya masyarakat secara kultural tumbuh kembagkan dalam budaya patuh (feodal).

Selain itu kabupaten Solok yang sudah berdiri selama 107 tahun, seharusnya sudah menjadi kabupaten yang mapan dan mampu memanfaatkan dan mengembangkan Sumber Daya Alam (SDA) dan Sumber Daya Manusia (SDM) sehingga bisa menjadi kabupaten yag matang, baik dari segi ekonomi, pembangunan, politik, social budaya. Akan tetapi dengan realita yang ada PAD Kabupaten Solok masih rendah, karena banyak potensi alam dan lainnya masih belum tergarap secara maksimal.

Secara konsepsi, otonomi daerah seharusnya tidak membebani masyarakat, tetapi justru memberi motivasi, memberdayakan dan membangkitkan prakarsa serta mendorong partisipasi masyarakat dalam upaya pembangunan sehingga otonomi akan menumbuhkan kemandirian dalam mengatur dan mengurus rumah tangga sendiri (Salam, 2004).

Kabupaten Solok setelah otonomi daerah tentu menginginkan menjadi kabupaten yang matang baik sebagai pusat kegiatan ekonomi, politik, sosial, maupun pembangunan. Oleh karena itu penelitian ini berupaya mendeskripsikan perubahan ekonomi dan pembangunan di Kabupaten Solok pasca otonomi daerah. Pada penelusuran literature juga ditemukan tulisan yang membahas perkembangan peraturan perundang-undangan tentang otonomi daerah (Christia \& Ispriyarso, 2019) dan sejarah perkembangan otonomi daerah di Indonesia (Safitri, 2016). Selanjutnya juga ada tulisan mengenai implementasi kebijakan otonomi daerah bidang pendidikan, kesehatan, dan perekonomian di Kabupaten Bandung Barat (Lambelanova, 2017). Akan tetapi belum ada peneliti temukan tulisan mengenai perubahan ekonomi, pembangunan, sosial dan budaya setelah otonomi daerah di Kabupaten solok.

\section{METODE}

Pendekatan yang digunakan dalam penelitian ini adalah pendekatan kualitatif. Menurut Bodgan dan Taylor, pendekatan kualitatif merupakan prosedur penelitian yang menghasilkan data deskriptif yang berupa kata-kata yang tertulis maupun lisan dari orang-orang dan perilaku yang dapat diamati, hal tersebut diarahkan pada latar individu secara holistik atau secara utuh (Lexy, 1998). Alasan peneliti menggunakan pendekatan kualitatif yaitu, agar penelitian ini dapat menggali secara mendalam mengenai perubahan sosial dan pembangunan di Kabupaten Solok pasca otonomi daerah.

Data yang diperoleh dengan cara megamati langsung (observasi), wawancara dan dokumentasi. Serta peneliti melakukan analisa dengan analisis data kualitatif yang di populerkan oleh Miles dan Huberman. Teknik analisis data yang digunakan dalam penelitian ini yaitu seperti yang dikemukakan oleh Milles dan A. Huberman yang terdiri dari beberapa tahap yaitu reduksi data, penyajian data dan penarikan kesimpulan (Sugiono 2010:146-247). 


\section{HASIL DAN PEMBAHASAN}

Kabupaten Solok memiliki luas wilayah sebesar $3.738 \mathrm{~km} 2$ dan secara geografis terletak diantara 01o 20' 27" sampai 01o 21'39" Lintang Selatan dan 100o 25' sampai 100o 37' Bujur Timur. Topografi wilayah sangat bervariasi antara dataran, lembah, berbukit-bukit dengan ketinggian antara 329 meter - 1.458 meter di atas permukaan laut.

Dilihat dari sudut pandang letak Kabupaten Solok, posisinya sangat strategis karena disamping dilewati jalur Jalan Lintas Sumatera dan berbatasan langsung dengan Kota Padang sebagai Ibukota Propinsi. Adapun batas-batas wilayah Kekuatan Solok diantaranya (1) Sebelah Utara: Kabupaten Tanah Datar; (2) Sebelah Selatan: Kabupaten Solok Selatan; (3) Sebelah Barat: Kota Padang, Kabupaten Padang Pariaman dan Kabupaten Pesisir Selatan.

Gambar 1. Tugu Ayam sebagai Landmark Kabupaten Solok

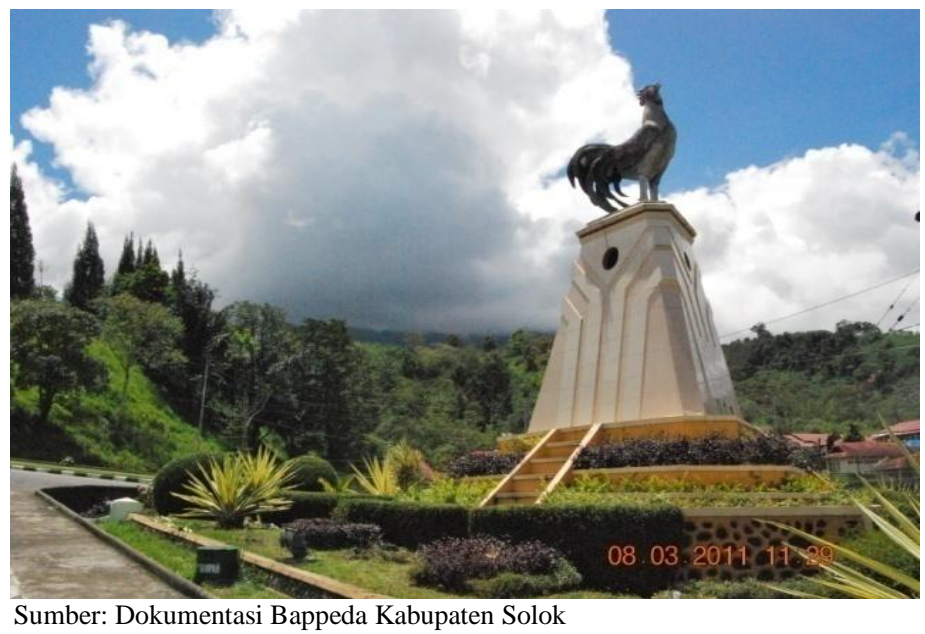

Adapun perubahan Sosial dan Pembangunan di Kabupaten Solok setelah otonomi daerah, dapat dilihat dari beberapa aspek berikut:

\section{Sektor Ekonomi dan Pembangunan}

Peraturan-peraturan yang di wewenangkan pada pemerintah daerah juga mengenai peraturan perekonomian. Perekonomian pemerintah daerah diperoleh melalui potensi daerah masing-masing (Ristanti \& Handoyo, 2017). Adapun beberapa aspek yang menonjol dalam perkembangan dan perekonomian di Kabupaten Solok, yaitu tampak pada sektor pertanian, sektor perumahan dan listrik yang digunakan masyarakat dalam aktifitas kesehariannya.

Dinas Pertanian memiliki tugas pokok melaksanakan urusan pemerintah daerah berdasarkan asas otonomi dan tugas pembantuan di bidang pertanian sesuai dengan kewenangannya. Untuk terselenggaranya tugas pokok di atas, maka Dinas Pertanian Kabupaten Solok mempunyai fungsi sebagai berikut: (1) Perumusan kebijakan teknis di bidang pertanian; (2) Penyelenggaraan urusan pemerintahan dan pelayanan umum di bidang pertanian; (3) Pembinaan dan Pelaksanaan tugas di bidang pertanian; (4) Pelaksanaan tugas lain yang diberikan oleh Bupati sesuai tugas dan fungsinya.

Gubernur Sumatera Barat menetapkan kawasan pertanian tanaman pangan dan hortikultura provinsi Sumatera Barat dengan Keputusan Gubernur Sumatera Barat No. 521.305.2013 tentang Penetapan Kawasan Pertanian Tanaman Pangan dan Hortikultura Sumatera Barat. Pada keputusan ini Kawasan Gunung Talang ditetapkan sebagai kawasan padi di Sumatera Barat, kawasan Alahan Panjang, kawasan Danau Kembar dan kawasan Gunung Talang ditetapkan sebagai kawasan sayur di Sumatera Barat, kawasan Batang Barus dan kawasan Aia Batumbuak ditetapkan sebagai kawasan tanaman hias di Sumatera Barat. Serta beberapa kawasan di Kabupaten Solok ditetapkan sebagai Kawasan Sentra Utama Pertanian sesuai dengan Keputusan Bupati Solok No. 520-286-2017 tanggal 22 Mei 2017. Adapun hasil pertaniannya berupa sayur, kopi, kakao, cengkeh, karet, jeruk, alpukat, padi markisa, krisan dan teh.

Pertumbuhan perumahan dan permukiman di Kabupaten Solok pada umumnya berkembang pesat seiring dengan pertambahan penduduk yang mengakibatkan bertambahnya kebutuhan perumahan. Akan tetapi belum 
semuanya mampu disediakan oleh Pemerintah Kabupaten bahkan dalam penyediaan prasarana dan sarana dasarnya. Sehingga sering kali dijumpai kawasan perumahan yang di alokasikan oleh pemerintah kabupaten Solok menjadi kawasan kumuh dan tidak layak huni.

Pola perumahan, atau rumah penduduk di kabupaten Solok di bagi menjadi tiga bagian, yaitu: rumah sederhana, sedang dan mewah. Menurut data pada dokumen Penyusunan Rencana Pembangunan dan Pengembangan Perumahan dan Permukiman Daerah (RP4D) Kabupaten Solok, rincian rumah yang ada di masyarakat Kabupaten Solok adalah seperti yang di gambarkan pada tabel di bawah ini:

Tabel 1. Kategori Perumahan Penduduk

\begin{tabular}{rlrr}
\hline No & & Tipe Rumah & Jumlah \\
& & & \\
\hline 1 & Sederhana & & 54600 \\
$\mathbf{2}$ & Menengah & & 27300 \\
$\mathbf{3}$ & Mewah & \multirow{2}{*}{ Jumlah } & 9100 \\
& & & 91000 \\
\hline
\end{tabular}

Berdasarkan tabel di atas, dapat diketahui bahwa $60 \%$ masyarakat di Kabupaten Solok tinggal di rumah sederhana. Sedangkan sisanya tinggal di rumah menengah (30\%) dan mewah (10\%). Dari keseluruhan stok rumah di Kabupaten Solok tersebut tidak semuanya dalam kondisi yang baik. Terdapat beberapa rumah yang berada dalam kondisi rusak dan rusak berat.

Seiring perkembangan zaman listrik sudah menjadi kebutuhan primer bagi setiap masyarakat, baik dari golongan menengah maupun atas, oleh karena itu listrik menjadi infrastruktur yang sangat di butuhkan oleh masyarakat. Sehubungan dengan Pertumbuhan Sistem Ketenagalistrikan, jenis pelanggan menurut penggunaan energi listrik terdiri atas pelanggan rumah tangga, industri, bisnis, sosial dan pemerintahan. Sampel pengguna listrik Tahun 2007-2012 Kabupaten Solok mengalami pertumbuhan jumlah pelanggan rata-rata untuk rumah tangga sebesar 2,57\%, sosial sebesar 2,79\%, bisnis sebesar 11,24\% dan industri sebesar 19,44\% dan pemerintahan sebesar 2,51\%. Periode selama 4 tahun tersebut pertumbuhan beban sektor industri mengalami pertumbuhan yang paling besar, dan ini melihatkan tumbuhnya industri di Kabupaten Solok cukup baik.

\section{Sektor Sosial budaya}

Kabupaten solok yang memiliki 14 kecamatan dan pola sosial budaya yang berbeda akan tetapi tetap menjunjung tinggi nilai, aturan dan norma yang telah di tentukan oleh pemerintah daerah. Dan pemerintah membentuk kinerja layanan urusan wajib Bidang Sosial di Kabupaten Solok Tahun 2010 sampai Tahun 2015 menunjukkan perkembangan yang cukup baik, dalam bidang urusan sosial hal ini dapat dilihat dari data pada tabel berikut:

Tabel 2. Perkembangan Indikator Kinerja Bidang Urusan Sosial di Kabupaten Solok Tahun 2010-2015

\begin{tabular}{|c|c|c|c|c|c|c|c|}
\hline \multirow[t]{2}{*}{ NO } & \multirow[t]{2}{*}{ Indikator } & \multicolumn{6}{|c|}{ Tahun } \\
\hline & & 2010 & 2011 & 2012 & 2013 & 2014 & 2015 \\
\hline 1 & Sarana sosial seperti & 4 Panti & 4 Panti & 4 Panti & 4 Panti & 4 Panti & 4 Panti \\
\hline & $\begin{array}{l}\text { panti asuhan, panti } \\
\text { jompo dan panti } \\
\text { rehabilitasi }\end{array}$ & Asuhan & Asuhan & Asuhan & Asuhan & Asuhan & Asuhan \\
\hline 2 & $\begin{array}{l}\text { Penanganan } \\
\text { penyandang masalah } \\
\text { kesejahteraan sosial / } \\
\text { penanganan PMKS }(\%)\end{array}$ & 48,64 & 24,98 & 94,76 & 11,11 & 11,11 & 80,82 \\
\hline 3 & Jumlah PMKS & 14.809 & 14.854 & 7.755 & 12.125 & 12.125 & 12.013 \\
\hline
\end{tabular}

Sumber : Dinas Sosial, Tenaga Kerja dan Transmigrasi Kab. Solok tahun 2016

Berdasarkan data tersebut dapat dilihat bahwa kinerja urusan sosial yang ditunjukan oleh indikator Penanganan PMKS mengalami kenaikan menjadi 80,82 \% pada Tahun 2015. Hal ini disebabkan karena semakin 
tingginya perhatian pemerintah untuk mengentaskan kemiskinan sehingga tahun 2015 telah dibantu sebanyak 12.013 PMKS.

Kabupaten Solok yang kaya akan kebudayaannya juga mengalami perkembangan dalam aktivitas seni dan budaya. Analisis kinerja seni dan budaya dapat dilihat pada indikator jumlah grup kesenian. Perkembangan terhadap indikator tersebut dapat dilihat pada tabel berikut ini:

Tabel 3. Perkembangan Indikator Kinerja Fokus Kebudayaan di Kabupaten Solok Tahun 2010-2015

\begin{tabular}{|c|c|c|c|c|c|c|c|}
\hline \multirow[t]{2}{*}{ No } & \multirow[t]{2}{*}{ Indikator } & \multicolumn{6}{|c|}{ Tahun } \\
\hline & & 2010 & 2011 & 2012 & 2013 & 2014 & 2015 \\
\hline 1 & Jumlah Grup Kesenian & 160 & 165 & 170 & 175 & 177 & 177 \\
\hline 2 & $\begin{array}{l}\text { Jumlah } \\
\text { Penyelenggaraan Seni dan } \\
\text { Budaya }\end{array}$ & 6 & 6 & 6 & 6 & 6 & 5 \\
\hline 3 & $\begin{array}{l}\text { Penyelenggaraan festival } \\
\text { seni dan budaya }\end{array}$ & 2 & 2 & 3 & 2 & 2 & 2 \\
\hline 4 & $\begin{array}{l}\text { Benda, situs dan kawasan } \\
\text { cagar } \\
\text { dilestarikan }(\%)\end{array}$ & 64 & 65,71 & 71,43 & 85,71 & 89,19 & 94,59 \\
\hline
\end{tabular}

Sumber : Disdikpora dan Disbudpar Tahun 2016

Berdasarkan Tabel diatas dapat dilihat bahwa kinerja di bidang kebudayaan dapat dilihat dari kegiatan yang dilakukan dalam rangka mendukung kelestarian budaya di Kabupaten Solok antara lain penyelenggaraan festival seni dan budaya serta pelestarian terhadap Benda, Situs dan Kawasan Cagar Budaya. Kinerja di bidang ini dapat dilihat dari persentase pelestarian Benda, Situs dan Kawasan Cagar Budaya pada Tahun 2015 yang mencapai 94,59 persen. Sementara itu jumlah grup kesenian dan penyelenggaraan festival seni dan budaya tidak mengalami peningkatan, jumlah sarana penyelenggaraan seni dan budaya mengalami penurunan dari tahun 2014.

\section{KESIMPULAN}

Perkembangan kabupaten Solok setelah otonomi daerah menunjukkan perubahan pada beberapa aspek, baik dari aspek ekonomi dan pembangunan maupun aspek sosial dan budaya. Perubahan yang terjadi pada aspek ekonomi dan pembangunan tampak: (1) Pada sektor pertanian dengan ditetapkannya beberapa kawasan sebagai kawasan sentra utama pertanian di Kabupaten Solok sesuai dengan Keputusan Bupati Solok No. 520-286-2017 tanggal 22 Mei 2017. (2) Sedangkan pada sektor perumahan, pertumbuhan perumahan dan permukiman di Kabupaten Solok pada umumnya berkembang pesat seiring dengan pertambahan penduduk yang mengakibatkan bertambahnya kebutuhan perumahan. Akan tetapi belum semuanya mampu disediakan oleh Pemerintah Kabupaten. Sehingga sering kali dijumpai kawasan perumahan yang di alokasikan oleh pemerintah kabupaten Solok menjadi kawasan kumuh dan tidak layak huni. (3) Perkembangan sektor ekonomi lainnya terlihat pada penggunaan istrik Tahun 2007-2012 Kabupaten Solok yang mengalami pertumbuhan jumlah pelanggan rata-rata untuk rumah tangga sebesar 2,57\%, sosial sebesar 2,79\%, bisnis sebesar 11,24\% dan industri sebesar 19,44\% dan pemerintahan sebesar $2,51 \%$. Sedangkan pada sektor sosial budaya menunjukkan perkembangan yang cukup baik dalam bidang urusan sosial. Perkembangan di Kabupaten Solok tampak pada penanganan Penyandang Masalah Kesejahteraan Sosial / penanganan PMKS serta di bidang kebudayaan dapat dilihat dari kegiatan yang dilakukan dalam rangka mendukung kelestarian budaya di Kabupaten Solok seperti penyelenggaraan festival seni dan budaya serta pelestarian terhadap benda, situs dan kawasan cagar budaya.

\section{DAFTAR RUJUKAN}

Anggun Ciptasari Nurana; Lutfi Muta'ali. (2009). Analisis Dampak Kebijakan Otonomi Daerah Terhadap Ketimpangan Perkembangan Wilayah Di Kawasan Ciayumajakuning. Jurnal of Economic, 172-181.

Christia, A. M., \& Ispriyarso, B. (2019). Desentralisasi Fisikal dan Otonomi Daerah di Indonesia. Law Reform, 15(1), 149. https://doi.org/10.14710/lr.v15i1.23360

Kuncoro. (2004). Otonomi dan Pembangunan Daerah: Reformasi, Perencanaan, Strategi dan Peluang. Yogyakarta: Erlangga.

Lambelanova, R. (2017). The policy implementation of autonomy area the fields of education, health and 
economy in west bandung district. Sosiohumaniora, 19(2), 185-198.

Lexy, M. (1998). Metode Penelitian Kualitatif. Bandung: PT. Remaja Rosda karya.

Ristanti, Y. D., \& Handoyo, E. (2017). Undang-Undang Otonomi Daerah Dan Pembangunan Ekonomi Daerah. Jurnal Riset Akutansi Keuangan, 2(2), 115-122.

Safitri, S. (2016). Sejarah Perkembangan Otonomi Daerah Di Indonesia. Jurnal Criksetra, 5(9), $79-83$.

Salam, D. S. (2004). Otonomi Daerah Dalam Perspektif Lingkungan, Nilai dan Sumber Daya. Jakarta: Djambatan.

Sugiyono. 2012. Metode Penelitian Kuantitatif kualitatif dan R\&B. Bandung: ALFABET

Triani, M. (2015). Analisis Kebijakan Otonomi Daerah Terhadap Pertumbuhan Ekonomi Di Sumatera Barat Dalam Menghadapi Masyarakat Ekonomi ASEAN. (c), 9. 